\title{
Determination of Total Fluoride in Boron-containing Solutions
}

\author{
Siqingaowa BorJIGIN, ${ }^{*}$ Toshiaki YoshIOKA, ${ }^{* \dagger}$ and Tadaaki MIzoguCHI** \\ *Graduate School of Environmental Studies, Tohoku University, 6-6-7 Aramaki Aza Aoba, Aoba, \\ Sendai 980-8579, Japan \\ **Environment Conservation Research Institute, Tohoku University, 6-6-11 Aramaki Aza Aoba, Aoba, \\ Sendai 980-8579, Japan
}

\begin{abstract}
We describe a pretreatment method before determining the total fluoride in solutions containing tetrafluoroborate ion $\left(\mathrm{BF}_{4}^{-}\right)$with ion-selective electrodes (ISEs). $\mathrm{BF}_{4}^{-}$was quantitatively converted to free fluoride by reacting with aluminum ions. The total fluoride concentration was then determined by ISE analysis without preliminary steam distillation using a tartrate- and tris(hydroxymethyl)methylamine (TRIS)-based total ionic strength adjustment buffer (TISAB). We investigated the effects of various factors on the decomposition of $\mathrm{BF}_{4}^{-}$with aluminum ions, including the concentration of aluminum, $\mathrm{pH}$, reaction temperature, and reaction time. The quantitative decomposition of $\mathrm{BF}_{4}^{-}{ }^{-}$was complete after $2 \mathrm{~h}$ at $50^{\circ} \mathrm{C}$ or $1 \mathrm{~h}$ at $70^{\circ} \mathrm{C}$.
\end{abstract}

(Received February 17, 2009; Accepted March 23, 2010; Published May 10, 2010)

\section{Introduction}

Ion-selective electrodes (ISEs) for the quantification of the total amount of fluoride have been employed in a variety of scientific fields due to their relatively simple construction and use. ISEs, however, measure the activity of free fluoride. Determining the total fluoride concentration with ISEs is not trivial, when samples contain fluoride bound to ions, such as aluminum and boron, since the total concentration of fluoride often cannot be readily calculated from its activity.

Although interference from coexisting ions can be mostly eliminated by steam distillation prior to analysis, ${ }^{1,2}$ this process is both time- and labor-intensive. An alternative method described herein involves the use of a tartrate- and tris(hydroxymethyl)methylamine (TRIS)-based total ionic strength adjustment buffer (TISAB). ${ }^{3}$ This method offers a high detection efficiency for fluoride, even in the presence of $100 \mathrm{mg} \mathrm{L}^{-1}$ aluminum.

The flue gas emitted from coal-fired boilers ${ }^{4-6}$ contains both fluorine and boron. ${ }^{7-9}$ Most of these components are removed upstream at the flue-gas desulfurization plant by a pre-scrubber that removes dust and water-soluble gases; e.g. $\mathrm{HCl}, \mathrm{HF}$, and lowers the flue gas temperature. The pre-scrubber circulation liquid is highly acidic, i.e., $\mathrm{pH}$ 1. This liquid usually contains fluoride and boron in the form of $\mathrm{BF}_{4}^{-}$, along with aluminum ions from dissolved dust particles. The wastewater from a pre-scrubber typically contains $100-1500 \mathrm{mg} \mathrm{L}^{-1}$ fluoride and 200 - $1500 \mathrm{mg} \mathrm{L}^{-1}$ aluminum.

The fluoride content can be reliably determined by ISE analysis at concentrations as low as $10 \mathrm{mg} \mathrm{L}^{-1}$. Thus, the fluoride content in pre-scrubber wastewater can be accurately measured even after considerable dilution. When diluted by a

† To whom correspondence should be addressed.

E-mail: yoshioka@env.che.tohoku.ac.jp factor of 20, the concentration of aluminum is decreased to between 10 and $75 \mathrm{mg} \mathrm{L}^{-1}$. Using the tartrate- and TRIS-based TISAB method with an ISE, as described previously for sample solutions in the absence of boron, ${ }^{3}$ this level of coexisting aluminum does not interfere significantly with the determination of fluoride.

For an accurate ISE measurement of the total fluoride content in such samples as pre-scrubber wastewater that contain boron, however, $\mathrm{BF}_{4}^{-}$must be quantitatively converted into free fluoride ions prior to analysis. The present authors have investigated the formation and decomposition of $\mathrm{BF}_{4}^{-}$in $\mathrm{H}_{3} \mathrm{BO}_{3}-\mathrm{Al}^{3+}-\mathrm{F}^{-}$solutions via experiments and thermodynamic calculations, and have shown that the fluoride in $\mathrm{BF}_{4}^{-}$can be converted to fluoroaluminate by adding an aluminum salt solution under acidic conditions. ${ }^{10}$ In addition to this study on the formation and decomposition of $\mathrm{BF}_{4}^{-}$, we have also shown that total fluoride content in solutions containing a large amount of aluminum can be determined by ISE analysis using a tartrate- and TRIS-based TISAB solution. ${ }^{3}$ By combining these characteristics of $\mathrm{BF}_{4}{ }^{-}$and fluoride, a novel pretreatment method before determining total fluoride in solutions containing $\mathrm{BF}_{4}^{-}$ with ISEs is proposed. In the current study, we have investigated the decomposition of $\mathrm{BF}_{4}^{-}$under various conditions, including $\mathrm{pH}$, concentration of $\mathrm{Al}^{3+}$, reaction temperature, and reaction time in order to obtain basic information on the ISE analysis of total fluoride in boron-containing solutions.

\section{Experimental}

\section{Apparatus}

Fluoride ion concentrations were measured with a fluoride-ion-selective electrode (F-2021; DKK-TOA Corporation, Tokyo, Japan) and a portable ion-pH meter (IM-22P; DKK-TOA Corporation). 


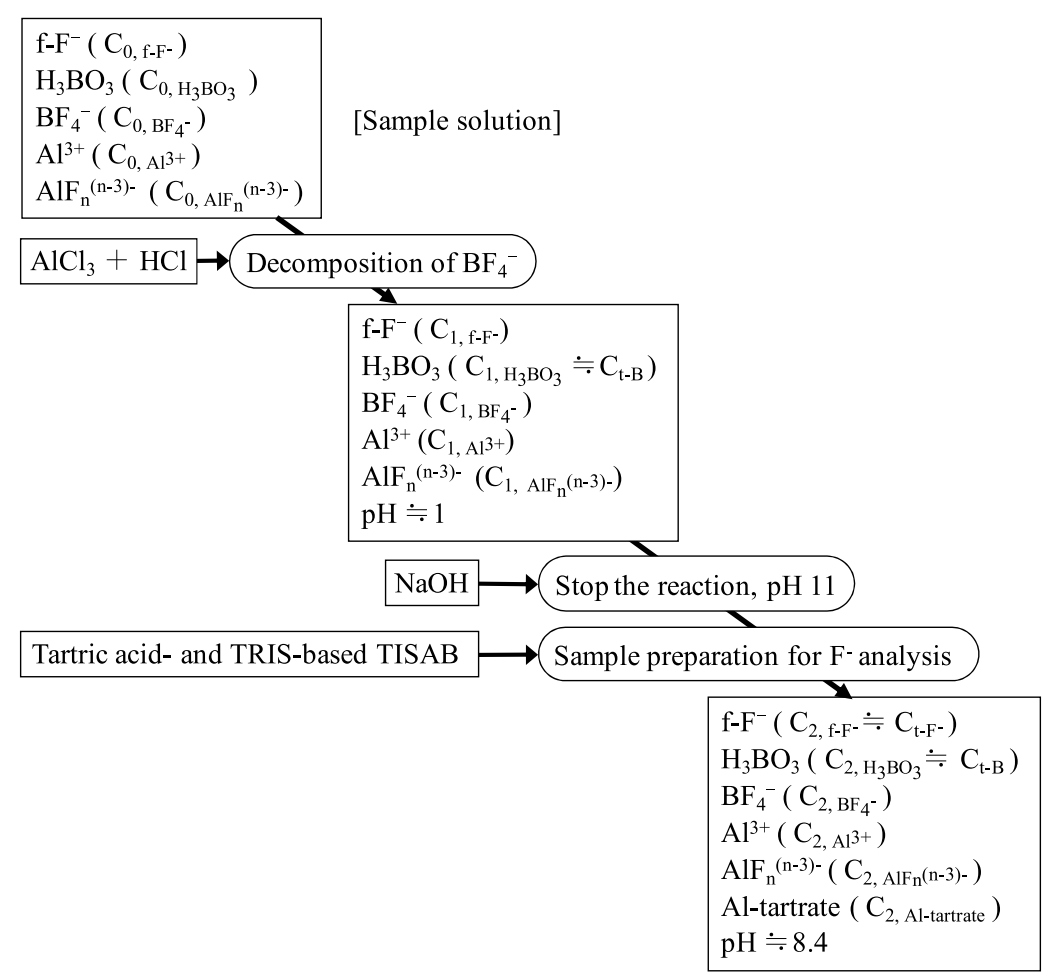

Fig. 1 Schematic diagram showing the determination of total fluoride in boron-containing solutions by ISE analysis.

\section{Reagents}

Unless otherwise stated, all chemicals were of analytical reagent grade, and were used without further purification. Distilled and demineralized water was used throughout this study. Sodium tetrafluoroborate $\left(\mathrm{NaBF}_{4}\right)$ was obtained from Kanto Chemical Co., Inc. (Tokyo, Japan) and purified as follows. An amount of $\mathrm{NaBF}_{4}$ was dissolved in water at $80^{\circ} \mathrm{C}$ to obtain a nearly saturated solution. The solution was hot filtered through a $0.45-\mu \mathrm{m}$ filter (Millipore, Billerica, MA) and refrigerated to obtain $\mathrm{NaBF}_{4}$ crystals. The crystals were separated by filtration and washed with a 1:1 water:methanol solution, followed by neat methanol. The crystals were dried under vacuum overnight in a desiccator containing sulfuric acid.

\section{Determination of total fluoride in $\mathrm{BF}_{4}^{-}$solutions}

The standard procedure of total fluoride determination by ISE method was as follows. A wide-necked, $50-\mathrm{mL}$ polyethylene bottle was charged with $2 \mathrm{~mL}$ of water, $10 \mathrm{~mL}$ of $2000 \mathrm{mg} \mathrm{L}^{-1}$ $\mathrm{F}^{-}\left(4.420 \mathrm{~g} \mathrm{~L}^{-1} \mathrm{NaF}\right), 2 \mathrm{~mL}$ of $2000 \mathrm{mg} \mathrm{L}^{-1} \mathrm{BF}_{4}^{-}\left(2.530 \mathrm{~g} \mathrm{~L}^{-1}\right.$ $\left.\mathrm{NaBF}_{4}\right), 2 \mathrm{~mL}$ of $1 \mathrm{M} \mathrm{HCl}$, and $4 \mathrm{~mL}$ of $5000 \mathrm{mg} \mathrm{L}^{-1} \mathrm{Al}^{3+}$ (44.74 $\mathrm{g} \mathrm{L}^{-1} \quad \mathrm{AlCl}_{3}$ ). This yields a solution containing $1000 \mathrm{mg} \mathrm{L}^{-1}$ free $\mathrm{F}^{-}, 200 \mathrm{mg} \mathrm{L}^{-1} \mathrm{BF}_{4}^{-}\left(175.1 \mathrm{mg} \mathrm{L}^{-1}\right.$ as free $\left.\mathrm{F}^{-}\right)$, and $1000 \mathrm{mg} \mathrm{L}^{-1} \mathrm{Al}^{3+}$ at $\mathrm{pH} \mathrm{1}$, assuming that no reactions occurred among the constituents. The bottle was sealed and immersed in a water bath at $50^{\circ} \mathrm{C}$. The bottle was held at this temperature for $2 \mathrm{~h}$ and cooled to room temperature. The resulting solution was transferred to a $100-\mathrm{mL}$ volumetric flask containing $5 \mathrm{~mL}$ of $1.6 \mathrm{M} \mathrm{NaOH}$, and diluted to the mark with water. The $\mathrm{pH}$ of the solution was approximately 11 , with no observable precipitate of aluminum hydroxide. Note that $\mathrm{BF}_{4}^{-}$ was neither formed nor decomposed during this procedure.

Six milliliters of this stock solution were placed in a $100-\mathrm{mL}$ volumetric flask and diluted to the mark with water. The total concentration of $\mathrm{F}^{-}$at this stage was $14.1 \mathrm{mg} \mathrm{L}^{-1}$ and $12.0 \mathrm{mg} \mathrm{L}^{-1}$ originating from $\mathrm{NaF}$ and the rest from $\mathrm{NaBF}_{4}$.

A solid mixture consisting of tartaric acid, sodium tartrate, tris(hydroxymethyl)methylamine, and sodium chloride (0.75:1.15:2.42:0.59 by weight, $4.91 \mathrm{~g}$ total) was added to a $50-\mathrm{mL}$ aliquot of the above-mentioned solution, and the fluoride concentration was determined by ISE analysis. Calibration curves were generated using a standard sodium fluoride solution. Details regarding the determination of fluoride by ISE analysis have been described elsewhere. ${ }^{3}$

\section{Results and Discussion}

Principle of the determination of the total fluoride concentration in boron-containing solutions

The principle of total fluoride determination in boron-containing solutions, which is illustrated in Fig. 1, is based on the following findings, reported previously. ${ }^{10,11} \mathrm{BF}_{4}^{-}$is not formed at $\mathrm{pH}$ higher than 3.5. The formation degree of $\mathrm{BF}_{4}^{-}$ increases with increasing fluoride concentration and/or decreasing aluminum concentration. $\mathrm{BF}_{4}^{-}$, once formed, is very stable under higher $\mathrm{pH}$ conditions. $\mathrm{BF}_{4}{ }^{-}$is decomposed by adding aluminum compounds at $\mathrm{pH}$ lower than 4 according to the following reaction:

$n \mathrm{BF}_{4}^{-}+4 \mathrm{Al}^{3+}+3 n \mathrm{H}_{2} \mathrm{O}=4 \mathrm{AlF}_{n}^{(n-3)-}+n \mathrm{H}_{3} \mathrm{BO}_{3}+3 n \mathrm{H}^{+}$.

Concentration changes due to dilution are not taken into consideration in Fig. 1. The initial amount of fluoride was assumed to be free $\mathrm{F}^{-}$(concentration: $\left.C_{0, \mathrm{f}-\mathrm{F}}\right)$ and $\mathrm{BF}_{4}^{-}\left(C_{0, \mathrm{BF}_{4}}\right)$. The boron content was assumed to be free boric acid, $\mathrm{H}_{3} \mathrm{BO}_{3}$ $\left(C_{0, \mathrm{H}_{3} \mathrm{BO}_{3}}\right)$ and $\mathrm{BF}_{4}^{-}\left(C_{0, \mathrm{BF}_{4}^{-}}\right)$. Aluminum was assumed to be present as free $\mathrm{Al}^{3+}\left(C_{0, \mathrm{Al}^{3+}}\right)$ and fluoroaluminates, $\mathrm{AlF}_{\mathrm{n}}{ }^{(\mathrm{n}-3)-}$

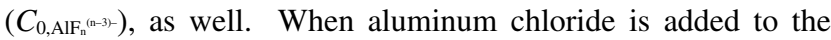




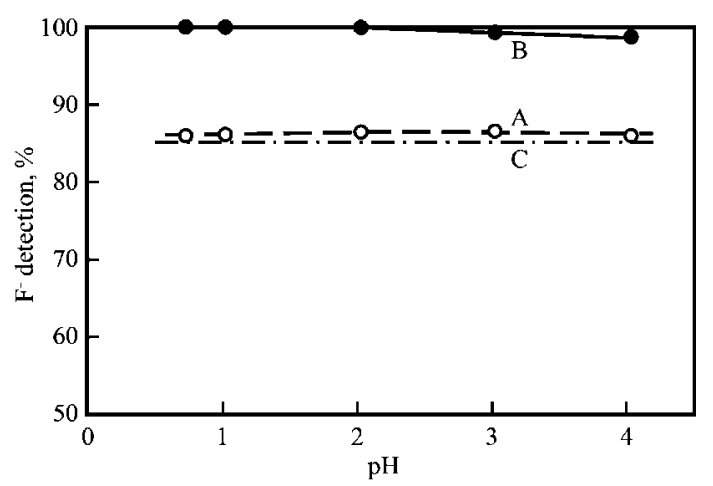

Fig. 2 Effect of $\mathrm{pH}$ on the decomposition of $\mathrm{BF}_{4}^{-}$. Initial concentration of free fluoride, $1000 \mathrm{mg} \mathrm{L}^{-1}$; initial concentration of $\mathrm{BF}_{4}^{-}, 200 \mathrm{mg} \mathrm{L}^{-1}$; reaction temperature, $50^{\circ} \mathrm{C}$; reaction time, $2 \mathrm{~h}$. Concentration of aluminum added $\left(\mathrm{mg} \mathrm{L}^{-1}\right)$ : $\mathrm{A}, 0 ; \mathrm{B}, 1000$. Line $\mathrm{C}$ represents the fraction of free fluoride of the total fluoride in both cases $\mathrm{A}$ and $\mathrm{B}$.

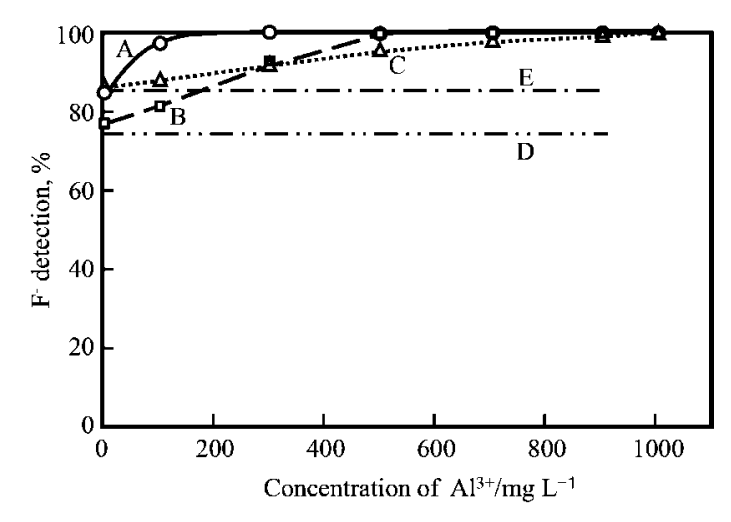

Fig. 3 Effect of the aluminum concentration on the decomposition of $\mathrm{BF}_{4}^{-}$. Initial concentration of $\mathrm{BF}_{4}^{-}, 200 \mathrm{mg} \mathrm{L}^{-1} ; \mathrm{pH}, 1$; reaction temperature, $50^{\circ} \mathrm{C}$; reaction time, $2 \mathrm{~h}$. Initial concentration of free fluoride (mg L-1): A, 0; B, 500; C, 1000. Lines D and E represent the fraction of free fluoride of the total fluoride in cases B and C, respectively.

solution after acidification to $\mathrm{pH} 1$ with $\mathrm{HCl}$, the concentrations of free $\mathrm{F}^{-}, \mathrm{BF}_{4}^{-}, \mathrm{H}_{3} \mathrm{BO}_{3}$, free $\mathrm{Al}^{3+}$, and $\mathrm{AlF}_{\mathrm{n}}{ }^{(\mathrm{n}-3)-}$ ions become

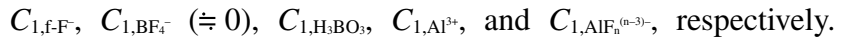
Note that $\mathrm{BF}_{4}^{-}$no longer exists, and boron exists exclusively as $\mathrm{H}_{3} \mathrm{BO}_{3} .{ }^{10}$

Upon adding the resulting reaction mixture to a sodium hydroxide solution to obtain an alkaline solution having a $\mathrm{pH}$ value of about 11 , not only the decomposition, but also formation of $\mathrm{BF}_{4}^{-}$does not proceed any more. ${ }^{10}$ On the subsequent addition of tartrate- and TRIS-based TISAB, the $\mathrm{pH}$ is adjusted to 8.4, and aluminum and fluoride exist exclusively as tartrate complexes (concentration: $\left.C_{2, \mathrm{Al} \text {-tartrate }}\right)$ and free $\mathrm{F}^{-}\left(C_{2, \mathrm{~F}}\right)$, respectively. The determination of total fluoride by ISE then becomes feasible. The point is that the detection degree of fluoride depends only the decomposition conditions of $\mathrm{BF}_{4}^{-}$, and the ISE analysis is not affected by the presence of boron at $\mathrm{pH} 8.4$, since the decomposition and the formation of $\mathrm{BF}_{4}{ }^{-}$do not occur under these conditions. ${ }^{10}$

Based on the equilibria estimated by a thermodynamic calculation, ${ }^{10}$ the conversion degree of $\mathrm{BF}_{4}^{-}$to boric acid was higher than $99.9 \%$ at $\mathrm{pH} 1$ for a mixed solution shown in the standard procedure.

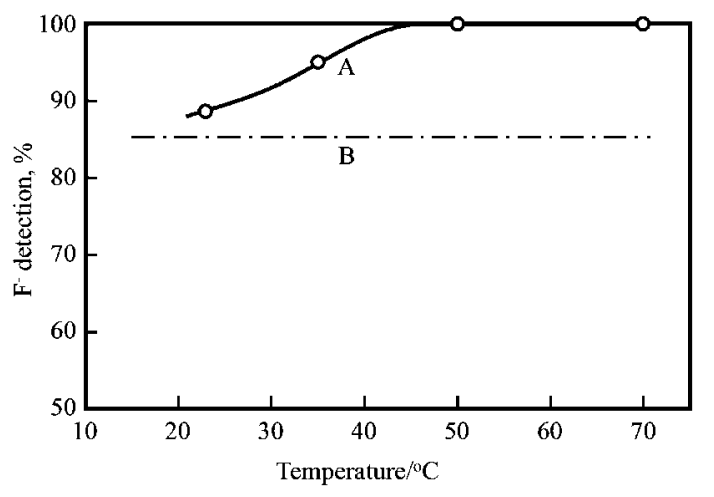

Fig. 4 Effect of the reaction temperature on the decomposition of $\mathrm{BF}_{4}^{-}$. Initial concentration of free fluoride, $1000 \mathrm{mg} \mathrm{L}^{-1}$; initial concentration of $\mathrm{BF}_{4}^{-}, 200 \mathrm{mg} \mathrm{L}^{-1}$; concentration of aluminum added, $1000 \mathrm{mg} \mathrm{L}^{-1} ; \mathrm{pH}, 1$; reaction time, $2 \mathrm{~h}$. Lines A and $\mathrm{B}$ represent the experimental results and the fraction of free fluoride of the total fluoride, respectively.

\section{Effect of $p H$}

The decomposition of $\mathrm{BF}_{4}{ }^{-}$was performed as a function of the solution $\mathrm{pH}$ by adjusting the amount of $\mathrm{HCl}$ added under the standard conditions described above. The relationship between the fluoride detection efficiency and the solution $\mathrm{pH}$ after the decomposition of $\mathrm{BF}_{4}^{-}$is shown by the open circles in Fig. 2 . The decomposition of $\mathrm{BF}_{4}^{-}$to $\mathrm{F}^{-}$was quantitative at $\mathrm{pH} 2$ or lower, demonstrating the feasibility of total fluoride determination by ISE analysis. In the absence of $\mathrm{AlCl}_{3}$, the conversion of $\mathrm{BF}_{4}^{-}$to $\mathrm{F}^{-}$was as low as several percent, and the total fluoride detection efficiency was as low as $86 \%$, regardless of the solution $\mathrm{pH}$.

\section{Effect of aluminum concentration}

The decomposition of $\mathrm{BF}_{4}^{-}$was performed using different concentrations of free fluoride: 0,500 , and $1000 \mathrm{mg} \mathrm{L}^{-1} \mathrm{~F}^{-}$. The relationship between the efficiency of fluoride detection and the aluminum concentration is shown in Fig. 3. The minimum concentrations of $\mathrm{Al}^{3+}$ required to obtain a fluoride detection efficiency of $99 \%$ or more were 500 and $900 \mathrm{mg} \mathrm{L}^{-1}$, in the presence of 500 and $1000 \mathrm{mg} \mathrm{L}^{-1} \mathrm{~F}^{-}$, respectively.

On the other hand, for solutions without free fluoride, fluoride detection efficiencies greater than $99 \%$ were obtained by adding $300 \mathrm{mg} \mathrm{L}^{-1} \mathrm{Al}^{3+}$. The detection efficiency of fluoride in $\mathrm{BF}_{4}^{-}$ solutions without free fluoride was as high as $84 \%$, even in the absence of $\mathrm{Al}^{3+}$. This may most likely be due to the following reaction under acidic conditions:

$$
\mathrm{BF}_{4}^{-}+\mathrm{H}^{+}+3 \mathrm{H}_{2} \mathrm{O}=\mathrm{H}_{3} \mathrm{BO}_{3}+4 \mathrm{HF} \text {. }
$$

According to a thermodynamic calculation, ${ }^{10}$ the fraction of free fluoride was as high as $64 \%$ when a $200 \mathrm{mg} \mathrm{L}^{-1} \mathrm{BF}_{4}^{-}$ solution was in an equilibrium state at $\mathrm{pH} 1$.

These results demonstrate that the total fluoride ion concentration can be determined in sample solutions containing both $\mathrm{F}^{-}$and $\mathrm{BF}_{4^{-}}$, in amounts comparable to those in pre-scrubber wastewater, using the ISE method with the addition of a tartrateand TRIS-based TISAB solution.

\section{Effect of reaction temperature}

The decomposition of $\mathrm{BF}_{4}^{-}$by aluminum was performed primarily at $50^{\circ} \mathrm{C}$, comparable to the pre-scrubber liquid temperature in flue gas desulfurization plants. ${ }^{10}$ To examine the 


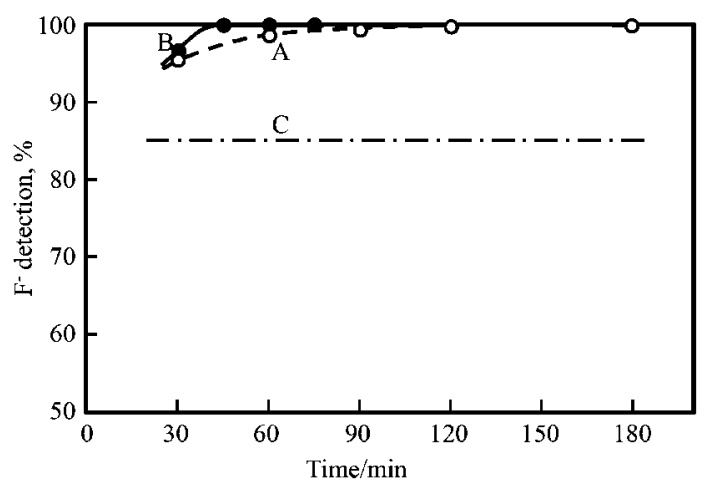

Fig. 5 Effect of the reaction time on the decomposition of $\mathrm{BF}_{4}{ }^{-}$at 50 and $70^{\circ} \mathrm{C}$. Initial concentration of free fluoride, $1000 \mathrm{mg} \mathrm{L}^{-1}$; initial concentration of $\mathrm{BF}_{4}^{-}, 200 \mathrm{mg} \mathrm{L}^{-1}$; concentration of aluminum added, $1000 \mathrm{mg} \mathrm{L}^{-1} ; \mathrm{pH}, 1$. Reaction temperature $\left({ }^{\circ} \mathrm{C}\right)$ : A, 50; $\mathrm{B}, 70$.

effects of the reaction temperature on the decomposition process, experiments were also performed at $23,35,50$, and $70^{\circ} \mathrm{C}$. The relationship between the fluoride detection efficiency and the reaction temperature is shown in Fig. 4. The detection efficiency was as high as $100 \%$ at 50 and $70^{\circ} \mathrm{C}$, and as low as 95 and $89 \%$ at 35 and $23^{\circ} \mathrm{C}$, respectively. These results show that $2 \mathrm{~h}$ is sufficient for quantitative decomposition at temperatures above $50^{\circ} \mathrm{C}$, with longer reaction times required at lower temperatures. The thermostability of the polyethylene bottles, however, dictates that the reaction should be performed at temperatures lower than $70^{\circ} \mathrm{C}$.

\section{Effect of reaction time}

In accordance with the above results, the relationship between the detection efficiency of fluoride and the reaction time was investigated at 50 and $70^{\circ} \mathrm{C}$. The results are shown in Fig. 5 . The times required to obtain detection efficiencies higher than $99 \%$ were 90 and $45 \mathrm{~min}$ at 50 and $70^{\circ} \mathrm{C}$, respectively. The quantitative decomposition of $\mathrm{BF}_{4}^{-}$was therefore complete after $2 \mathrm{~h}$ at $50^{\circ} \mathrm{C}$ or $1 \mathrm{~h}$ at $70^{\circ} \mathrm{C}$. These results were verified by repeated experiments, with the fluoride detection efficiency being as high as $100 \%$ in each case.

\section{Conclusions}

The total fluoride concentration can be accurately determined in the presence of aluminum, without any sample pretreatment, using an ISE method incorporating a tartrate- and TRIS-based TISAB solution. ${ }^{3}$ In solutions that contain $\mathrm{BF}_{4}^{-}$, the total fluoride content can still be measured by ISE analysis using a tartrate- and TRIS-based TISAB solution. Fluoride present as $\mathrm{BF}_{4}{ }^{-}$is decomposed to fluoroaluminate by aluminum ions under acidic conditions. ${ }^{10}$ The fluoroaluminate formed can be determined as free fluoride by ISE analysis using a tartrate- and TRIS-based TISAB solution. The quantitative decomposition of $\mathrm{BF}_{4}^{-}$was complete after $2 \mathrm{~h}$ at $50^{\circ} \mathrm{C}$ or $1 \mathrm{~h}$ at $70^{\circ} \mathrm{C}$.

The procedure described here allows determining the total fluoride content by ISE without steam distillation. The level of interferences from common ions and the precision of the present ISE method may be the same as those reported previously. ${ }^{3}$ This ISE method is simple to operate and can be applied to a variety of samples, including wastewaters from flue-gas desulfurization plants, sediment samples, and incineration ashes.

\section{References}

1. ASTM D1179-04, "Standard Test Methods for Fluoride Ion in Water", 2004, American Society for Testing and Materials.

2. JIS K0102, "Testing Methods for Industrial Wastewater", 2003, Japanese Industrial Standard.

3. S. Borjigin, Y. Ashimura, T. Yoshioka, and T. Mizoguchi, Anal. Sci., 2009, 25, 1437.

4. H. Asada and Y. Etoh, Environ. Conserv. Eng., 2000, 29, 283.

5. S. Shirakura, Y. Etoh, T. Takadoi, and T. Miura, The Thermal and Nuclear Power, 1982, 33, 1319.

6. H. Ohsumi, S. Ohyama, S. Kudo, and M. Sakata, Central Research Institute of Electric Power Industry, Komae Research Laboratory Rep. No. T02012, 2003.

7. R. D. Smith, Prog. Energy Combust. Sci., 1980, 6, 53.

8. A. H. Clemens, L. F. Damiano, D. Gong, and T. W. Matheson, Fuel, 1999, 78, 1379.

9. A. H. Clemens, J. M. Deely, D. Gong, T. A. Moore, and J. C. Shearer, Fuel, 2000, 79, 1781.

10. J. Katagiri, S. Borjigin, T. Yoshioka, and T. Mizoguchi, J. Mater. Cycles Waste Manag., in press.

11. J. Katagiri, T. Yoshioka, and T. Mizoguchi, Anal. Chim. Acta, 2006, 570, 65. 